\title{
Retinopathy predicts stroke but not myocardial infarction in type 2 diabetes: the Fremantle Diabetes Study Phase II
}

\author{
Jocelyn J. Drinkwater ${ }^{1}$, Timothy M. E. Davis ${ }^{1 *}$ (D, Valentina Hellbusch ${ }^{1}$, Angus W. Turner ${ }^{2,3}$, David G. Bruce ${ }^{1}$ \\ and Wendy A. Davis ${ }^{1}$
}

\begin{abstract}
Background: Microangiopathy in type 2 diabetes (T2D) is associated with cardiovascular disease (CVD), but most relevant studies were performed $>10$ years ago. CVD risk factor management has since improved. The aim of this study was to determine whether diabetic retinopathy (DR) and its severity increases stroke and myocardial infarction (MI) risk in a contemporary cohort.

Methods: Fremantle Diabetes Study Phase II participants with T2D had DR graded from fundus photography at baseline between 2008 and 2011. Subsequent hospitalizations and mortality for MI or stroke were ascertained through validated data linkage to end-2016. Cox regression modelling identified predictors of first stroke and MI including DR presence and severity.

Results: The 1521 participants with T2D and known DR status (mean age 65.6 years, 52.1\% males, median diabetes duration 9.0 years) were followed for a mean of 6.6 years. After excluding those with prior Ml/stroke, there were 126 incident Mls among 1393 eligible participants and 53 incident strokes in 1473 eligible participants, respectively. Moderate non-proliferative DR (NPDR) or worse was significantly and independently associated with an increased risk of incident stroke (adjusted hazard ratio 2.55 ( $95 \% \mathrm{Cl} 1.19,5.47), p=0.016)$. Retinopathy presence and severity increased the risk of incident $\mathrm{Ml}$ in unadjusted models ( $p \leq 0.001)$, but these associations were no longer statistically significant after adjusting for other risk factors.
\end{abstract}

Conclusions: Moderate NPDR or worse was associated with an increased risk of first stroke in Australians with T2D. Intensified CVD risk factor management should be considered for patients with at least moderate NPDR.

Keywords: Diabetes mellitus, Type 2, Diabetic retinopathy, Stroke, Myocardial infarction

\section{Background}

Diabetic retinopathy (DR) is a microvascular complication characterized by microaneurysms, exudates and hemorrhages [1]. Although largely preventable, it affects about a third of people with diabetes [2] and is a leading cause of vision loss [1]. There is some evidence of a

*Correspondence: tim.davis@uwa.edu.au

${ }^{1}$ Medical School, The University of Western Australia, Fremantle Hospital, P. O. Box 480, Fremantle, WA 6959, Australia

Full list of author information is available at the end of the article link between microvascular disease and the macrovascular complications of type 2 diabetes (T2D) [3]. However, few studies have specifically assessed the relationship between DR and the individual clinical manifestations of cardiovascular disease (CVD). Most of these have involved only stroke as an outcome, and some lacked robust ascertainment of diabetes type and CVD endpoints. In addition, most were conducted more than 10 years ago [4-11] at a time when CVD risk factor management was becoming more intensive [12] and CVD event rates were declining in people with and without

c) The Author(s) 2020. This article is licensed under a Creative Commons Attribution 4.0 International License, which permits use, sharing, adaptation, distribution and reproduction in any medium or format, as long as you give appropriate credit to the original author(s) and the source, provide a link to the Creative Commons licence, and indicate if changes were made. The images or other third party material in this article are included in the article's Creative Commons licence, unless indicated otherwise in a credit line to the material. If material is not included in the article's Creative Commons licence and your intended use is not permitted by statutory regulation or exceeds the permitted use, you will need to obtain permission directly from the copyright holder. To view a copy of this licence, visit http://creativeco mmons.org/licenses/by/4.0/. The Creative Commons Public Domain Dedication waiver (http://creativecommons.org/publicdomain/ zero/1.0/) applies to the data made available in this article, unless otherwise stated in a credit line to the data. 
diabetes [13, 14]. In Australia, for example, the incidence of stroke in the general population decreased by $23 \%$ between 2001 and 2015 and the rate of acute coronary artery disease events by 39\% between 2007 and 2013 [15].

Knowledge of the relationship between the microvascular and macrovascular complications of T2D has important implications for screening and risk factor management [16]. In light of this and the recent marked changes in CVD epidemiology in T2D, the aim of the present study was to determine whether the presence and/or severity of DR is associated with incident stroke and myocardial infarction (MI) in a well characterized, contemporary Australian community-based cohort.

\section{Methods}

\section{Participants and approvals}

The Fremantle Diabetes Study Phase II (FDS2) is a community-based, prospective, observational study involving participants with known diabetes from a zip code defined urban community of approximately 157,000 people surrounding the port of Fremantle in the state of Western Australia (WA). Residents within the catchment area with a physician confirmed diabetes diagnosis, and those who had participated in the Fremantle Diabetes Study Phase I (FDS1) but had moved out of the catchment area, were eligible. Sample characteristics including classification of diabetes type and details of those identified but not recruited have been described previously [17]. Briefly, 4639 people with diabetes were identified and 1668 (36\%) recruited together with 64 former FDS1 participants. Of these 1732, 1551 (90\%) had clinically diagnosed T2D. The study protocol conformed to the ethical guidelines of the 1975 Declaration of Helsinki.

\section{Clinical assessment}

All FDS2 participants underwent a detailed face-toface assessment at study entry and biennially [17]. Each included questionnaires covering health care utilization, medical conditions, medication use, and socioeconomic, demographic and lifestyle data. Treatment history, body mass index (BMI), age at diagnosis, nature of initial presentation, case record and/or self-identification, and available serum glutamic acid decarboxylase antibody titers were used to determine diabetes type. Non-insulin treated participants and those $\geq 60$ years of age at diagnosis were usually considered to have T2D, as were participants $<60$ years of age at diagnosis and taking insulin at the time of study entry but whose first treatment was not insulin [18].

A physical examination was conducted by trained registered nurses according to a standard protocol which included visual acuity measured using a Bailey Lovie chart at a distance of 3 metres in a well-lit room, fundus photography using a Canon CR-DGi Non-Mydriatic Retinal Camera, and electrocardiograms which were assessed for relevant abnormalities including atrial fibrillation. Biochemical tests were performed on fasting blood and first morning urine samples using standard automated methods in a single nationally accredited laboratory [18]. The plasma N-terminal pro-B-type natriuretic peptide concentration (NT-proBNP) was measured by commercial assay with inter-day imprecision $\leq 4.0 \%$ at concentrations up to $406 \mathrm{pg} / \mathrm{mL}$ and a limit of detection of $5 \mathrm{pg} / \mathrm{mL}$.

\section{Assessment of diabetic retinopathy}

Baseline fundus photographs were assessed independently by a single external grader who was accredited by the Centre for Eye Research Australia, University of Melbourne, and who was blinded to other participant data. Diabetic retinopathy was categorized using the modified Airlie House Classification system for the Early Treatment Diabetic Retinopathy Study (ETDRS). The severity of DR was classified as none, mild non-proliferative diabetic retinopathy (NPDR), moderate NPDR, or severe NPDR or worse. Level 10 was classified as no DR, levels 11-31 were categorized as mild NPDR, levels 41 and 84 were considered moderate NPDR and levels 51-80 and 86 were classified as severe NPDR or worse. For participants who did not have fundus photography performed or had ungradable photographs, further information regarding DR status and severity was sought from hospital records, optometrists and ophthalmologists. Those participants who had no information regarding DR status at baseline were excluded from analysis.

\section{Ascertainment of stroke and myocardial infarction}

The Hospital Morbidity Data Collection and the Registry for Births, Deaths and Marriages together capture all hospitalizations and deaths within the state of Western Australia. These sources were accessed for the FDS2 participants through the Western Australian Data Linkage System (WADLS) [19]. The data were used to determine the stroke and MI status and follow-up time ascertained to end-December 2016 using relevant ICD-9-CM and ICD-10-AM diagnosis and procedure codes (Additional file 1: Table SI). The admission date was considered the date of the event. Those who had had an event prior to participating in FDS2 were excluded from the relevant analysis. Causes of death, based on information provided on the death certificate or by the coroner's determination of cause of death, were reviewed independently by two study physicians (DGB, TMED) and classified under the system used in the UK Prospective Diabetes Study [20]. In the case of discrepant coding, case notes were consulted and a consensus obtained. Participants assessed to 
have died due to a cardiac or cerebrovascular event were considered as having the respective event in analysis.

Stroke was further classified into four different subtypes, specifically ischemic, hemorrhagic, intracranial hemorrhage, and unspecified, using ICD coding. To determine accuracy of using ICD codes for ascertaining stroke type, medical notes were compared to the ICD coding for 36 cases (67.9\%) where both were available, and all were concordant. In three cases medical records were used to ascertain stroke type as the ICD code used was I64 (stroke not specified as hemorrhage or infarction).

\section{Statistical analysis}

Statistical analyses were conducted using the computer packages IBM SPSS for Windows (Version 25.0 Armonk, NY: IBM Corp) and Stata (Version 15.1, Stat Corp, College Station, Texas, USA). Data are presented as proportions, mean $\pm S D$, geometric mean (SD range) or median [interquartile range]. For independent samples, two-way comparisons for categorical variables were by Fisher's exact test, for normally or log-normally distributed continuous variables by independent samples $t$-test and for variables not conforming to normal or log-normal distribution by Mann-Whitney $U$-test. A two-tailed significance level of $p<0.05$ was used throughout the study.

Cox proportional hazards models, excluding DR variables, were used to determine the independent predictors of stroke and MI, separately. Diabetic retinopathy presence and severity were then added to the most parsimonious models to determine if they were independent risk factors for stroke and MI. This method was repeated for specific stroke types. Age was used as the timescale with left truncation of age at study entry. Variables were considered for model entry based on clinical relevance and $p<0.20$ in bivariate analysis. Variables considered for model entry included age, sex, diabetes duration, diabetes treatment, $\mathrm{HbA}_{1 \mathrm{c}}$, blood pressure, BMI, urinary albumin:creatinine ratio, lipids, hemoglobin and smoking status. Atrial fibrillation was considered in the stroke multivariable analyses, and angina and peripheral arterial disease were considered in the MI analysis. Additional Cox regression analyses were performed (i) including participants with prevalent stroke or MI events at baseline, and (ii) excluding participants with a history of ischemic heart disease, cerebrovascular disease, peripheral arterial disease and atrial fibrillation at baseline. The proportional hazards assumption was checked for each model using Schoenfeld global tests and time varying covariates. Since the FDS2 sample size was fixed, a post hoc calculation was performed for all non-significant results to determine whether there was sufficient power to avoid a type II error.

\section{Results}

\section{Participant disposition}

A participant flow diagram is shown in Fig. 1. Of 1551 with T2D, 1418 (91.4\%) had gradable fundus photography, whilst 103 (6.6\%) had ungradable fundus photography but DR status ascertained from other sources. One participant who had DR documented in the medical record but without classification of severity was conservatively assumed to have mild DR. Diabetic retinopathy status was not available for $30(1.9 \%)$ participants, who were excluded from analyses.

\section{Baseline characteristics}

The 1521 participants with DR status available had a mean \pm SD age of $65.6 \pm 11.5$ years at study entry, $52.1 \%$ were male and their median [IQR] diabetes duration was $9.0[2.9-15.8]$ years at study entry. There were 565 (37.1\%) participants who had DR of whom 444 (29.2\%) had mild NPDR, 68 (4.5\%) moderate NPDR and 52 (3.4\%) severe NPDR or worse. The 48 (3.2\%) participants who had suffered a stroke and 128 (8.4\%) who had experienced a MI prior to study entry were excluded from the respective analyses.

\section{Diabetic retinopathy and stroke}

During 9759 person-years of follow-up, a mean \pm SD follow up of $6.6 \pm 1.8$ years, there were 53 incident stroke events. Of these 53, there were $24(45.3 \%)$ ischemic, 12 (22.6\%) hemorrhagic, 8 (15.1\%) intracranial hemorrhages, and 9 (17.0\%) unclassified (see Table 1). In bivariate analysis, those who had a stroke during follow-up were older, had longer diabetes duration, a higher $\mathrm{HbA}_{1 \mathrm{c}}$, heart rate and supine systolic blood pressure, and were more likely to be on antihypertensive medication (see Table 2). They were more likely to have atrial fibrillation, poor renal function, anemia, peripheral arterial disease, to have had a MI prior to commencing the study, and to have had an eye examination in the previous year. Those who had a stroke were more likely to have moderate NPDR or worse $(7.3 \%$ vs $17.0 \%, p=0.016)$. However, there was no statistically significant association between any DR or DR severity (as an ordinal variable) at baseline and incident stroke, and a power calculation showed insufficient power to avoid a type II error $(<0.48)$. Similarly, there was insufficient power to assess the association between retinopathy and the different stroke types separately (see Additional file 1: Table SIV). Therefore, we assessed the association between moderate NPDR or worse with any incident stroke during follow-up.

The results of the Cox regression are shown in Table 3. Atrial fibrillation, urinary albumin:creatinine ratio and $\mathrm{HbA}_{1 \mathrm{c}}$ were independently associated with stroke in the most parsimonious model. When added to the most 


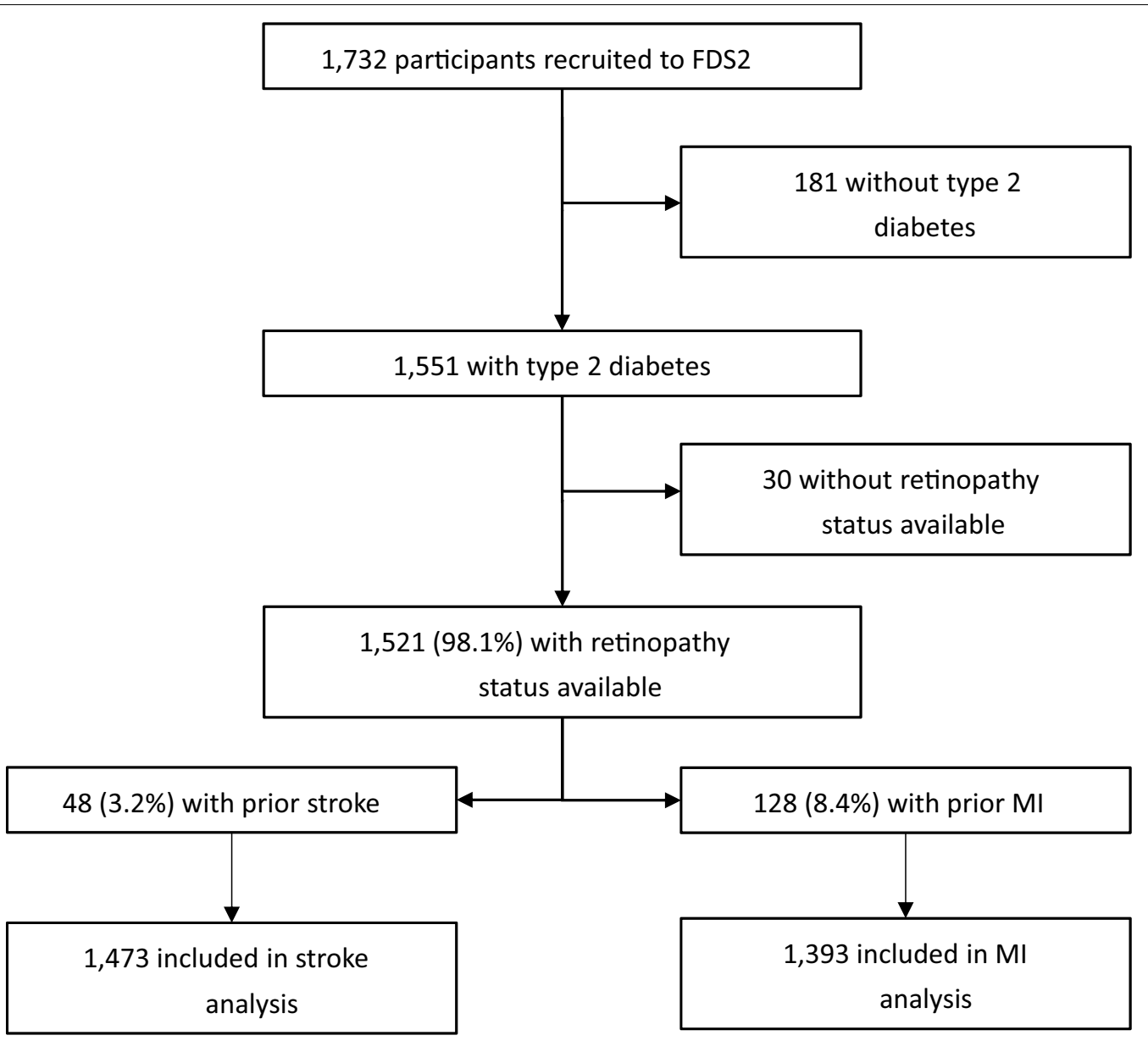

Fig. 1 Flow chart showing participants included in analyses

Table 1 The distribution (number (\%)) of diabetic retinopathy (DR) and retinopathy severity according to stroke status during follow-up

\begin{tabular}{llllll}
\hline & $\begin{array}{l}\text { No stroke } \\
\text { during follow-up }\end{array}$ & $\begin{array}{l}\text { Any stroke } \\
\text { during follow-up }\end{array}$ & Ischaemic stroke & Hemorrhagic stroke & $\begin{array}{l}\text { Strokes } \\
\text { excluding intracranial } \\
\text { hemorrhages }\end{array}$ \\
\hline $\begin{array}{l}\text { Number } \\
\text { Any DR }\end{array}$ & 1420 & 53 & 24 & 12 & 45 \\
$\begin{array}{l}\text { DR severity } \\
\text { None }\end{array}$ & $522(36.8)$ & $24(45.3)$ & $12(50.0)$ & $2(16.7)$ & $17(37.8)$ \\
Mild NPDR & $899(63.3)$ & $29(54.7)$ & $12(50.0)$ & $10(83.3)$ & $28(62.2)$ \\
Moderate NPDR & $418(29.4)$ & $15(28.3)$ & $7(29.2)$ & $1(8.3)$ & $11(24.4)$ \\
Severe NPDR or PDR & $61(4.3)$ & $5(9.4)$ & $2(8.3)$ & 0 & $2(4.4)$ \\
Moderate NPDR or worse & $42(3.0)$ & $4(7.5)$ & $3(12.5)$ & $1(8.3)$ & $4(8.9)$ \\
\hline
\end{tabular}

parsimonious model, moderate NPDR or worse was associated with an increased stroke risk compared to those with no DR or mild NPDR [HR: 2.55 (95\% CI 1.19, 5.47)] and $\mathrm{HbA}_{1 \mathrm{c}}$ was no longer a statistically significant predictor. Schoenfeld global tests and time-varying covariates showed that the proportional hazards assumption was met for these Cox regression models. The results of the additional Cox models are shown in Additional file 1: Tables SV-VII. Severe NPDR was independently associated with incident stroke in those without 
Table 2 Baseline characteristics of FDS2 participants by stroke status to end-2016

\begin{tabular}{|c|c|c|c|}
\hline Variables at baseline & No stroke during follow up & Stroke during follow up & $p$-value \\
\hline Number (\%) & $1420(96)$ & $53(4)$ & \\
\hline Age (years) & $65.1 \pm 11.4$ & $73.0 \pm 10.8$ & $<0.001$ \\
\hline Sex (\% male) & 51.8 & 52.8 & 0.89 \\
\hline Ethnic background (\%) & & & 0.22 \\
\hline Anglo-Celt & 53.7 & 52.8 & \\
\hline Southern European & 12.5 & 17.0 & \\
\hline Other European & 7.5 & 3.8 & \\
\hline Asian & 4.4 & 5.7 & \\
\hline Indigenous Australian & 6.3 & 0 & \\
\hline Mixed/other & 15.6 & 20.8 & \\
\hline Currently married/de facto (\%) & 63.6 & 54.7 & 0.19 \\
\hline Duration of diabetes (years) & $8.3[2.7-15.6]$ & $12.3[5.0-17.6]$ & 0.023 \\
\hline Diabetes treatment (\%) & & & 0.84 \\
\hline Diet & 24.1 & 20.8 & \\
\hline Oral agents \pm non-insulin injectables & 53.7 & 52.8 & \\
\hline Insulin only & 5.5 & 5.7 & \\
\hline Insulin + oral agents \pm non-insulin injectables & 16.7 & 20.8 & \\
\hline Fasting glucose (mmol/L) & $7.2[6.2-9.0]$ & $7.2[6.2-9.3]$ & 0.65 \\
\hline $\mathrm{HbA}_{1 c}(\%)$ & $6.8[6.2-7.7]$ & $7.3[6.4-8.1]$ & 0.045 \\
\hline $\mathrm{HbA}_{1 \mathrm{c}}(\mathrm{mmol} / \mathrm{mol})$ & $51[44-61]$ & $56[46-65]$ & 0.045 \\
\hline Severe hypoglycemia before baseline (\%) & 3.0 & 3.8 & 0.67 \\
\hline $\mathrm{BMI}\left(\mathrm{kg} / \mathrm{m}^{2}\right)$ & $31.3 \pm 6.2$ & $30.2 \pm 28.7$ & 0.20 \\
\hline Heart rate (bpm) & $70 \pm 12$ & $75 \pm 16$ & 0.014 \\
\hline Supine SBP (mm Hg) & $146 \pm 22$ & $155 \pm 20$ & 0.004 \\
\hline Supine DBP $(\mathrm{mm} \mathrm{Hg})$ & $80 \pm 12$ & $83 \pm 11$ & 0.18 \\
\hline Atrial Fibrillation on ECG (\%) & 3.5 & 17.7 & $<0.001$ \\
\hline Left ventricular hypertrophy on ECG (\%) & 2.0 & 0.0 & 0.62 \\
\hline On antihypertensive medication (\%) & 72.9 & 90.6 & 0.004 \\
\hline On ACE-I & 37.7 & 43.4 & 0.47 \\
\hline On ARB & 32.2 & 37.7 & 0.46 \\
\hline On beta-blocker & 21.5 & 30.2 & 0.13 \\
\hline On calcium channel blocker & 23.7 & 39.6 & 0.013 \\
\hline On lipid-modifying medication (\%) & 67.7 & 77.4 & 0.18 \\
\hline On aspirin (\%) & 36.6 & 47.2 & 0.15 \\
\hline On other anticoagulant (\%) & 11.7 & 20.8 & 0.05 \\
\hline On digoxin (\%) & 2.5 & 7.6 & 0.048 \\
\hline Total cholesterol (mmol/L) & $4.4 \pm 1.1$ & $4.3 \pm 1.1$ & 0.79 \\
\hline HDL-cholesterol (mmol/L) & $1.2 \pm 0.3$ & $1.3 \pm 0.3$ & 0.71 \\
\hline Serum triglycerides (mmol/L) & $1.5(0.9-2.6)$ & $1.6(1.0-2.6)$ & 0.35 \\
\hline Urinary albumin:creatinine (mg/mmol) & $3.1(0.8-11.4)$ & $6.7(1.4-31.5)$ & $<0.001$ \\
\hline eGFR (CKD-EPI) categories (\%) & & & 0.001 \\
\hline$\geq 90 \mathrm{~mL} / \mathrm{min} / 1.73 \mathrm{~m}^{2}$ & 39.8 & 20.8 & \\
\hline $60-89 \mathrm{~mL} / \mathrm{min} / 1.73 \mathrm{~m}^{2}$ & 44.8 & 43.4 & \\
\hline $45-59 \mathrm{~mL} / \mathrm{min} / 1.73 \mathrm{~m}^{2}$ & 8.5 & 17.0 & \\
\hline$<45 \mathrm{~mL} / \mathrm{min} / 1.73 \mathrm{~m}^{2}$ & 6.9 & 18.9 & \\
\hline Plasma NT-proBNP (pmol/L) & $74(18-311)$ & $163(46-582)$ & $<0.001$ \\
\hline Anemia (\%) & 10.6 & 20.8 & 0.039 \\
\hline Ischemic heart disease (\%) & 28.0 & 37.7 & 0.12 \\
\hline Angina before baseline (\%) & 20.4 & 26.4 & 0.30 \\
\hline
\end{tabular}


Table 2 (continued)

\begin{tabular}{llll}
\hline Variables at baseline & No stroke during follow up & Stroke during follow up & p-value \\
\hline Myocardial infarction before baseline (\%) & 8.2 & 17.0 & 35.9 \\
Peripheral arterial disease (\%) & 21.6 & 67.9 & 0.003 \\
Peripheral sensory neuropathy (\%) & 57.5 & $0.1[0-1.2]$ & 0.018 \\
Alcohol (standard drinks/day) & $0.1[0-1.2]$ & $46.2 / 46.2 / 7.7$ & 0.16 \\
Smoking status (\% never/ex/current) & $45.6 / 43.9 / 10.5$ & 93.9 & 0.95 \\
Had an eye test in the last year (\%) & 80.6 & 45.3 & 0.90 \\
Any retinopathy (\%) & 36.8 & & 0.015 \\
Retinopathy severity (\%) & & 54.7 & 0.25 \\
None & 63.3 & 28.3 & 0.06 \\
Mild non-proliferative only & 29.4 & 9.4 \\
Moderate non-proliferative only & 4.3 & 7.6 \\
Severe non-proliferative or worse & 3.0 & 17.0 \\
Moderate non-proliferative or worse (\%) & 7.3 & 0.016 \\
\hline
\end{tabular}

Data are percentages, mean $\pm S D$, geometric mean (SD range) or median [inter-quartile range]

Table 3 Model A shows the most parsimonious Cox model, with age as the timeline, for all incident stroke events. Model $B$ shows the addition of moderate non-proliferative diabetic retinopathy (NPDR) or worse to Model A

\begin{tabular}{|c|c|c|c|c|}
\hline \multirow[t]{2}{*}{ Baseline variable } & \multicolumn{2}{|l|}{ Model A } & \multicolumn{2}{|l|}{ Model B } \\
\hline & Cox model, HR (95\% Cl) & $p$-value & Cox model, HR (95\% Cl) & $p$-value \\
\hline $\mathrm{HbA}_{1 \mathrm{c}}$ (per 1\% increase) & $1.24(1.03,1.51)$ & 0.027 & $1.21(0.99,1.47)$ & 0.062 \\
\hline Atrial fibrillation & $3.20(1.50,6.84)$ & 0.003 & $3.50(1.62,7.56)$ & 0.001 \\
\hline Ln (urinary albumin:creatinine) ${ }^{a}$ & $1.34(1.12,1.61)$ & 0.002 & $1.30(1.08,1.56)$ & 0.006 \\
\hline Moderate NPDR or worse & & & $2.55(1.19,5.47)$ & 0.016 \\
\hline
\end{tabular}

a A 2.72-fold increase in urinary albumin:creatinine corresponds to an increase of 1 in $\ln ($ urinary albumin:creatinine)

any prior cardiovascular or cerebrovascular disease $[7.13$ (1.46, 34.79)]. Moderate NPDR or worse was associated with any stroke when those with a prior stroke at baseline were included $[2.21(1.04,4.66)]$.

\section{Diabetic retinopathy and myocardial infarction}

During 9189 person-years of follow-up, a mean \pm SD follow-up of $6.6 \pm 1.8$ years, there were 126 incident MIs. In bivariate analyses, those who had experienced a MI during follow-up were older, had longer diabetes duration, were more likely to be Indigenous Australians, current smokers, on insulin, have a history of severe hypoglycemia, angina, left ventricular hypertrophy, peripheral arterial disease, peripheral sensory neuropathy, higher systolic blood pressure, albuminuria, and worse kidney function (Additional file 1: Table SII). Incident MI was associated with the presence of any retinopathy (53.2\% in those with MI during follow-up vs $34.5 \%$ in those with no MI, $p<0.001)$, and greater DR severity $(p<0.001)$.

The results of the Cox regressions for MI are shown in Table 4. In the most parsimonious model (Additional file 1: Table SIII), age at diabetes diagnosis, $\mathrm{HbA}_{1 \mathrm{c}}$, current smoking, ln(plasma NT-proBNP), angina and peripheral arterial disease were independent risk factors for MI $(p \leq 0.007)$. Retinopathy status and severity were positively, but non-significantly associated with risk of MI when added to this model $(p>0.09)$. The results of the additional Cox regression that included participants with a prior MI at baseline also showed a significant association in unadjusted models but no independent association (Additional file 1: Table SVIII). There was insufficient power to assess the association between DR and $\mathrm{MI}$ in those without any prior cardiovascular or cerebrovascular history at baseline. The proportional hazards assumption was not violated in any of these Cox regressions models.

\section{Discussion}

The present study shows that, in representative, community-based people with T2D, moderate NPDR or worse at baseline was associated with a more than twofold increase in the risk of any subsequent stroke compared with mild NPDR or no DR after adjustment for a range of other important explanatory variables. Diabetic 
Table 4 The hazard ratios $(95 \% \mathrm{Cls})$ and significance levels of retinopathy presence and severity for an adjusted Cox model and when added to the most parsimonious Cox model for myocardial infarction with age as the timeline

\begin{tabular}{|c|c|c|c|c|}
\hline & $\begin{array}{l}\text { Unadjusted model, HR (95\% } \\
\text { Cl) }\end{array}$ & $p$-value & $\begin{array}{l}\text { Most parsimonious model, HR } \\
(95 \% \mathrm{Cl})^{\mathrm{a}}\end{array}$ & $p$-value \\
\hline Any retinopathy & $2.10(1.48,2.99)$ & $<0.001$ & $1.30(0.87,1.92)$ & 0.197 \\
\hline \multicolumn{5}{|l|}{ Retinopathy severity } \\
\hline None or mild NPDR & 1.00 (reference) & & 1.00 (reference) & \\
\hline Moderate NPDR & $3.15(1.74,5.69)$ & $<0.001$ & $1.73(0.91,3.29)$ & 0.095 \\
\hline Severe NPDR or worse & $3.11(1.56,6.22)$ & 0.001 & $1.02(0.48,2.18)$ & 0.958 \\
\hline $\begin{array}{l}\text { Moderate NPDR or worse vs mild NPDR } \\
\text { or no DR }\end{array}$ & $2.88(1.80,4.58)$ & $<0.001$ & $1.32(0.78,2.25)$ & 0.302 \\
\hline
\end{tabular}

${ }^{a}$ Adjusted for most parsimonious model which comprised age at diabetes diagnosis, $\mathrm{HbA1c}$, current smoker, In(NT-proBNP), angina and peripheral arterial disease

retinopathy status and its severity were associated with incident MI in bivariate analyses but were not independent risk factors after adjustment for other clinically relevant covariates. This is the first study to assess these relationships in a large contemporary cohort, an important consideration given that CVD epidemiology and risk factor management were much different to when most previous relevant studies were conducted. Although the present findings are consistent with those of most older studies, they have potential implications for current management of T2D and may provide further insight into the pathophysiology of its chronic vascular complications.

The relationship between diabetic retinopathy and stroke Several other studies have assessed the relationship between DR and stroke [4, 5, 7-9]. The most adjusted multivariable model from five of these cohort studies involving participants with any type of diabetes [4, 5, 7-9] were included in a recent meta-analysis that found that any DR was significantly associated with an increased risk of stroke (relative risk (RR) 1.74 (95\% CI $1.35,2.24)$ ) [11]. This is lower than the HR of 2.55 found in the present study for moderate NPDR or worse, but the meta-analysis did not include separate analyses based on DR severity. In addition, there were a number of methodologic differences between these and the present studies. The studies in the meta-analysis utilized different definitions and methods of assessing stroke, with three including self-reported stroke $[4,5,8]$ and one transient ischemic attacks [7], while one excluded strokes thought to be of cardioembolic origin including those related to atrial fibrillation [9]. By comparison, we ensured that our data were validated and categorized rigorously for both DR and stroke. The World Health Organization Multinational Study of Vascular Diseases in Diabetes (WHO MSVDD) [21], which was not included in the meta-analysis [11], found that any DR was significantly associated with an increased risk of stroke assessed from questionnaires in men and women with T2D (age-adjusted RR 2.1 (95\% CI 1.4, 3.2) and 2.4 (1.6, 3.4), respectively) [21]. Although these effect sizes are lower than those of the present study, this may be because we assessed those with worse DR. This suggests a dose response in that increasing DR severity is associated with a higher risk of stroke.

Some studies have shown that the severity of DR is associated with an increased stroke risk. The Action to Control Cardiovascular Risk in Diabetes (ACCORD) trial found an increasing risk of incident fatal or nonfatal stroke during follow-up for each step of DR severity [none, mild, moderate NPDR, to severe NPDR/ proliferative DR (PDR)] at baseline [22]. The ACCORD participants with severe NPDR/PDR at baseline had a significantly increased risk of stroke compared to those with no DR (HR 5.57 (95\% CI 2.40, 12.96), but this did not apply to those with mild or moderate NPDR [22]. It should be noted, however, that this was a selected sample of patients recruited to a clinical trial. In the Wisconsin Epidemiology Study of Diabetic Retinopathy (WESDR) there was a positive relationship between self-reported stroke and DR severity (OR 1.6 (95\% CI 1.1, 2.3) per retinopathy severity step (mild NPDR, moderate to severe NPDR and PDR)) in a type 1 diabetes cohort after 20 years of follow-up [4]. In the older-onset WESDR cohort, a significant relationship was found only between PDR and fatal stroke (HR $1.88(1.03,3.43))$ after 16 years of follow-up [5]. The Atherosclerosis Risk in Communities Study found a statistically significant relationship between ischemic stroke and any DR [HR: $2.34(1.13,4.86)]$ and also mild to moderate DR [HR: $2.43(1.32,4.50)]$ when compared to the participants with diabetes with no DR, but the association with severe DR was not significant [8]. Taken together with the present results, and notwithstanding between-study differences in patient sources, type of diabetes and stroke ascertainment, there is clear 
evidence that severe DR is associated with an increased stroke risk.

We were unable to assess the relationship between DR and type of stroke due to the small numbers in each subgroup and therefore a lack of statistical power. However, of interest is that there was a relatively low proportion of ischemic strokes in our cohort. In the Fenofibrate Intervention and Event Lowering in Diabetes (FIELD) trial, $81.4 \%$ of first strokes in people with T2D were ischemic and $9.9 \%$ hemorrhagic compared with $45.3 \%$ and $22.6 \%$ in the present study [23]. The FIELD trial data were collected from a younger selected participant sample between 1998 and 2005. Stroke rates have since declined [15] which may reflect a change in stroke distribution away from ischemic events. Indeed, the Global Burden of Disease 2013 Study estimated that $67 \%$ of incident strokes worldwide were ischemic and 33\% hemorrhagic [24].

\section{The relationship between diabetic retinopathy and myocardial infarction}

The relevant published literature linking DR and MI is inconsistent. Two other studies have similarly found no statistically significant association between DR and MI events, although the WESDR almost reached significance $(p=0.06)[4,25]$. The WHO MSVDD found a significant relationship between MI and DR only in type 1 diabetes [21]. The ACCORD trial reported a significant trend between each step of DR severity at baseline and incident fatal or non-fatal MI risk but, compared to those without DR, those with severe NPDR/PDR did not have an increased MI risk [22]. A large population-based cohort study using the UK Clinical Practice Research Datalink found that DR was associated with an increased risk of a major cardiovascular event (defined as either cardiovascular death, non-fatal MI or non-fatal ischemic stroke; HR: 1.39 [95\% CI 1.09, 1.76)] [26]. Similarly, the Cardiovascular Health study also showed participants with DR had increased odds of coronary heart disease or stroke [OR: 3.23 (95\% CI 1.09, 9.56)] [27]. A meta-analysis reported a significant association between DR and CVD but not specifically MI [10].

Although we did not find a significant independent association between DR and MI, there was a significant association between any DR and DR severity and MI in the unadjusted Cox models. An association between DR and $\mathrm{MI}$ is recognised in Europe in that the presence of DR is included in the assessment of cardiovascular risk promoted by the European Society of Cardiology [28]. One explanation for the lack of an independent association between DR and MI in the present study could be that patients with DR may also have autonomic neuropathy. This has been associated with a higher prevalence of asymptomatic MI events [29] which would not have been captured as an outcome in our study as they may not lead to hospitalization. Improved contemporary CVD risk management and increased use of preventive coronary revascularization procedures may have also attenuated an association.

\section{The association between microvascular and macrovascular disease in diabetes}

The link between microvascular and macrovascular complications in diabetes is controversial. A study comprising participants from a diabetes outpatient clinic found that the presence and number of microvascular complications was independently associated with all-cause mortality and cardiovascular events in type 1 diabetes during 10 years of follow-up [30]. The PRECISED study showed that DR presence and severity and microalbuminuria were associated with subclinical cardiovascular disease in people with type 2 diabetes [31]. Retinopathy has also been associated with subclinical carotid atherosclerosis in diabetes [32]. While there are few studies that have assessed the association between diabetes and carotid disease, some have found a significant association [33-36] but others did not [37-40]. Although the Rio de Janeiro type 2 diabetes cohort study found no association between carotid disease and new or worsening DR, participants with carotid disease and microvascular disease at baseline were more likely to have a cardiovascular event than those with carotid disease without microvascular complications [38]. Our results suggest that microvascular disease could be a predictor of macrovascular events as moderate NPDR or worse was independently associated with stroke.

\section{Potential mechanisms linking diabetic retinopathy and stroke}

A potential mechanism linking DR with stroke in T2D is the "common soil" hypothesis in which risk factors including hyperglycemia, hypertension and dyslipidemia are shared by these two complications [41]. Adjustment for these CVD risk factors in the multivariable model did not abolish the relationship between DR and stroke. In addition, when moderate NPDR or worse was added to the most parsimonious model, $\mathrm{HbA}_{1 \mathrm{c}}$ was no longer a significant predictor of stroke. A single baseline measurement of $\mathrm{HbA}_{1 \mathrm{c}}$, providing a measure of glycemia over the previous 3 months, may not adequately capture the effects of chronic glycemic exposure, which may be better represented by the presence of moderate NPDR or worse. In support of this, the weaker association between DR and stroke in our cohort compared with earlier studies could reflect more intensive contemporary long-term CVD risk factor management [13, 14, 42]. 
The present data suggest that, if DR and especially severe DR is detected on screening, CVD risk factor management should be intensified if necessary and consideration given to other relevant investigations such as carotid ultrasound.

An alternative explanation of the link between DR and stroke is that diabetes-related changes in the retinal microvasculature mirror those in the cerebral microvasculature [43]. In support of this hypothesis, there was a significant association between stroke and severe NPDR or worse when those with any cardiovascular or cerebrovascular disease at baseline were excluded. Cerebral microvascular damage associated with DR could augment the size and thus the neurologic manifestations of cerebral infarction or hemorrhage, thus increasing the likelihood of acute presentation and hospitalization. Recent literature suggests that DR may be a neurodegenerative disease, especially as the breakdown of the blood-retinalbarrier occurs early in the disease process [44] and is more marked in the presence of hyperglycemia [45]. This could also amplify the adverse neurologic effects of an acute intracerebral event. Adding weight to this hypothesis is the observation that, although significant in the unadjusted models, we found no independent association between incident MI and DR after adjustment. This could also reflect the "common soil" hypothesis, with CVD risk factors, even if only measured at baseline, explaining the bivariate relationship without the additional contribution of the close relationship between the retinal and cerebral microcirculations seen in the case of stroke.

\section{Strengths and limitations}

The strengths of the present study include comprehensive assessments in a large community-based sample, independent retinal grading, and near-complete ascertainment of DR status and CVD events using a well-validated data linkage system [19]. Limitations include that as ascertainment of stroke and MI events were by ICD coding through data accessed from WADLS, there is the possibility that some events may have been missed if they occurred outside WA. In addition, we had insufficient power to assess the relationship between DR and different types of stroke.

\section{Conclusions}

The present study found that at least moderate DR is an independent risk factor for stroke but not MI in people with T2D. The retinal microvasculature is readily observable and its appearances should be considered when CVD and especially stroke risk management is planned in T2D.

\section{Supplementary information}

Supplementary information accompanies this paper at https://doi. org/10.1186/s12933-020-01018-3.

Additional file 1: Additional Tables.

\section{Abbreviations}

ACCORD: The Action to Control Cardiovascular Risk in Diabetes; BMI: Body mass index; CVD: Cardiovascular disease; DR: Diabetic retinopathy; ETDRS: Early Treatment Diabetic Retinopathy Study; FDS1: Fremantle Diabetes Study Phase I; FDS2: Fremantle Diabetes Study Phase II; FIELD: Fenofibrate Intervention and Event Lowering in Diabetes; MI: Myocardial infaraction; NPDR: Non-proliferative diabetic retinopathy; NT-proBNP: N-terminal pro-B-type natriuretic peptide; PDR: Proliferative diabetic retinopathy; T2D: Type 2 diabetes; WA: Western Australia; WADLS: West Australian Data Linkage System; WHO MSVDD: World Health Organization Multinational Study of Vascular Diseases in Diabetes.

\section{Acknowledgements}

The authors wish to thank the Fremantle Diabetes Study Phase II staff, investigators and participants, the staff at the West Australian Data Linkage Branch, the Hospital Morbidity Data Collection, the Registry for Births, Deaths and Marriages, National Coronial Information System and the Victorian Department of Justice and Community Safety for use of Cause of Death Unit Record Files data.

\section{Authors' contributions}

JJD collected and analyzed the data and wrote the first draft of the manuscript. TMED is the Principal Investigator of the FDS and produced the final version of the manuscript. AWT and DGB (a Co-Investigator of FDS2) provided clinical interpretation of the data and reviewed/edited the manuscript. $\mathrm{VH}$ assisted with data collection and interpretation and reviewed/edited the manuscript. WAD, a Co-Investigator of FDS2, provided statistical advice, obtained the linked data, co-ordinated FDS2 and edited the manuscript. All authors read and approved the final manuscript.

\section{Funding}

The present study was supported by the National Health and Medical Research Council (project Grants 513781 and 1042231). JJD is supported by the Warren Jones UWA Postgraduate Research Scholarship and Australian Government Research Training Program Scholarship. TMED is supported by a National Health and Medical Research Council of Australia Practitioner Fellowship. Measurement of plasma NT-proBNP was supported by grants from the Novo Nordisk Regional Diabetes Support Scheme and the Fremantle Hospital Medical Research Foundation. The funding bodies had no involvement in the study design, data collection, analysis and interpretation of results or writing this manuscript.

\section{Availability of data and materials}

All supporting data are available within this article. Raw data are not publicly available due to restrictions regarding confidentiality, especially with data obtained through the Western Australian Data Linkage System.

\section{Ethics approval and consent to participate}

The South Metropolitan Area Health Service Human Research Ethics Committee approved FDS2 and written informed consent was obtained in each case.

\section{Consent for publication}

Not applicable.

\section{Competing interests}

The authors declare that they have no competing interests.

\section{Author details}

${ }^{1}$ Medical School, The University of Western Australia, Fremantle Hospital, P. O. Box 480, Fremantle, WA 6959, Australia. ${ }^{2}$ Lions Eye Institute, Nedlands, WA, Australia. ${ }^{3}$ Centre for Ophthalmology and Visual Science, University of Western Australia, Crawley, WA, Australia. 
Received: 21 January 2020 Accepted: 19 March 2020

Published online: 31 March 2020

\section{References}

1. Cheung N, Mitchell P, Wong TY. Diabetic retinopathy. Lancet. 2010;376(9735):124-36. https://doi.org/10.1016/S0140-6736(09)62124-3.

2. Kawasaki R, Cheung N, Islam FMA, Klein R, Klein BEK, Cotch MF, et al. Is diabetic retinopathy related to subclinical cardiovascular disease? Ophthalmology. 2011;118(5):860-5. https://doi.org/10.1016/j.ophth a.2010.08.040

3. Rosenson RS, Fioretto P, Dodson PM. Does microvascular disease predict macrovascular events in type 2 diabetes? Atherosclerosis. 2011;218(1):138. https://doi.org/10.1016/j.atherosclerosis.2011.06.029.

4. Klein BK, Klein R, McBride PE, et al. Cardiovascular disease, mortality, and retinal microvascular characteristics in type 1 diabetes: Wisconsin Epidemiologic Study of Diabetic Retinopathy. Arch Intern Med. 2004;164(17):1917-24. https://doi.org/10.1001/archinte.164.17.1917.

5. Klein R, Klein BK, Moss SE, Cruickshanks KJ. Association of ocular disease and mortality in a diabetic population. Arch Ophthalmol. 1999;117(11):1487-95. https://doi.org/10.1001/archopht.117.11.1487.

6. Kim Y-H, Hong M-K, Lee CW, Song J-M, Han K-H, Kang D-H, et al. Diabetic retinopathy as a predictor of late clinical events following percutaneous coronary intervention. J Invasive Cardiol. 2002;14(10):599-602.

7. Kawasaki R, Tanaka S, Tanaka S, Abe S, Sone H, Yokote K, et al. Risk of cardiovascular diseases is increased even with mild diabetic retinopathy: the Japan Diabetes Complications Study. Ophthalmology. 2013;120(3):57482. https://doi.org/10.1016/j.ophtha.2012.08.029.

8. Cheung N, Rogers S, Couper DJ, Klein R, Sharrett AR, Wong TY. Is diabetic retinopathy an independent risk factor for ischemic stroke? Stroke. 2007;38(2):398-401. https://doi.org/10.1161/01.STR.0000254547.91276 .50 .

9. Petitti DB, Bhatt HM. Retinopathy as a risk factor for nonembolic stroke in diabetic subjects. Stroke. 1995;26(4):593-6. https://doi.org/10.1161/01. STR.26.4.593.

10. Guo VY, Cao B, Wu X, Lee JJW, Zee BC-Y. Prospective association between diabetic retinopathy and cardiovascular disease - a systematic review and meta-analysis of cohort studies. J Stroke Cerebrovasc. 2016;25(7):1688-95. https://doi.org/10.1016/j.jstrokecerebrovasdis.

11. Zhu X-R, Zhang Y-P, Bai L, Zhang X-L, Zhou J-B, Yang J-K. Prediction of risk of diabetic retinopathy for all-cause mortality, stroke and heart failure: evidence from epidemiological observational studies. Medicine. 2017;96(3):e5894. https://doi.org/10.1097/MD.0000000000005894.

12. Lee M-S, Flammer AJ, Kim H-S, Hong J-Y, Li J, Lennon RJ, et al. The prevalence of cardiovascular disease risk factors and the Framingham Risk Score in patients undergoing percutaneous intervention over the last 17 years by gender: time-trend analysis from the Mayo Clinic PCI Registry. J Prev Med Public Health. 2014;47(4):216-29. https://doi.org/10.3961/ jpmph.2014.47.4.216.

13. Gregg EW, Li Y, Wang J, Burrows NR, Ali MK, Rolka D, et al. Changes in diabetes-related complications in the United States, 1990-2010. N Engl J Med. 2014;370(16):1514-23. https://doi.org/10.1056/NEJMoa1310799.

14. Harding JL, Pavkov ME, Magliano DJ, Shaw JE, Gregg EW. Global trends in diabetes complications: a review of current evidence. Diabetologia. 2019;62(1):3-16. https://doi.org/10.1007/s00125-018-4711-2.

15. Australian Institute of Health and Welfare. Cardiovascular disease snapshot. Cat. no. CVD 83. 2018. https://www.aihw.gov.au/reports/heart-strok e-vascular-disease/cardiovascular-health-compendium/contents/howmany-australians-have-cardiovascular-disease. Accessed 31 May 2019.

16. Chawla A, Chawla R, Jaggi S. Microvasular and macrovascular complications in diabetes mellitus: distinct or continuum? Indian J Endocrinol Metab. 2016;20(4):546-51. https://doi.org/10.4103/2230-8210.183480.

17. Davis TME, Bruce DG, Davis WA. Cohort profile: the Fremantle Diabetes Study. Int J Epidemiol. 2013;42(2):412-21. https://doi.org/10.1093/ije/ dys065.

18. Davis TME, Hunt K, Bruce DG, Starkstein S, Skinner T, McAullay D, et al. Prevalence of depression and its associations with cardio-metabolic control in Aboriginal and Anglo-Celt patients with type 2 diabetes: the Fremantle Diabetes Study Phase II. Diabetes Res Clin Pr. 2015;107(3):38491. https://doi.org/10.1016/j.diabres.2014.12.014.
19. Holman CDAJ, Bass AJ, Rouse IL, Hobbs MST. Population-based linkage of health records in Western Australia: development of a health services research linked database. Aust NZ J Publ Heal. 1999;23(5):453-9. https:// doi.org/10.1111/j.1467-842X.1999.tb01297.x

20. United Kingdom Prospective Diabetes Study Group. Intensive blood-glucose control with sulphonylureas or insulin compared with conventional treatment and risk of complications in patients with type 2 diabetes (UKPDS 33). Lancet. 1998;352(9131):837-53. https://doi.org/10.1016/ s0140-6736(98)07019-6.

21. Fuller JH, Stevens LK, Wang SL, the WHO Multinational Study Group. Risk factors for cardiovascular mortality and morbidity: the WHO Multinationa Study of Vascular Disease in Diabetes. Diabetologia. 2001;44(2):S54. https ://doi.org/10.1007/pl00002940.

22. Gerstein HC, Ambrosius WT, Danis R, Ismail-Beigi F, Cushman W, Calles J, et al. Diabetic retinopathy, its progression, and incident cardiovascular events in the ACCORD Trial. Diabetes Care. 2013;36(5):1266-71. https:// doi.org/10.2337/dc12-1311.

23. Hankey GJ, Anderson NE, Ting R-D, Veillard A-S, Romo M, Wosik M, et al. Rates and predictors of risk of stroke and its subtypes in diabetes: a prospective observational study. J Neurol Neurosurg Psychiatry. 2013;84(3):281-7. https://doi.org/10.1136/jnnp-2012-303365.

24. Feigin VL, Krishnamurthi RV, Parmar P, Norrving B, Mensah GA, Bennett DA, et al. Update on the global burden of ischemic and hemorrhagic stroke in 1990-2013: the GBD 2013 Study. Neuroepidemiology. 2015;45(3):161-76. https://doi.org/10.1159/000441085.

25. Torffvit O, Lövestam-Adrian M, Agardh E, Agardh CD. Nephropathy, but not retinopathy, is associated with the development of heart disease in Type 1 diabetes: a 12-year observation study of 462 patients. Diabetic Med. 2005;22(6):723-9. https://doi.org/10.1111/j.1464-5491.2005.01476.x.

26. Brownrigg JRW, Hughes CO, Burleigh D, Karthikesalingam A, Patterson BO, Holt PJ, et al. Microvascular disease and risk of cardiovascular events among individuals with type 2 diabetes: a population-level cohort study. Lancet Diabetes Endo. 2016;4(7):588-97. https://doi.org/10.1016/S2213 -8587(16)30057-2.

27. Klein R, Marino EK, Kuller LH, Polak JF, Tracy RP, Gottdiener JS, et al. The relation of atherosclerotic cardiovascular disease to retinopathy in people with diabetes in the Cardiovascular Health Study. Brit J Ophthalmol. 2002;86(1):84-90. https://doi.org/10.1136/bjo.86.1.84.

28. Cosentino F, Grant PJ, Aboyans V, Bailey CJ, Ceriello A, Delgado V, et al. 2019 ESC Guidelines on diabetes, pre-diabetes, and cardiovascular diseases developed in collaboration with the EASD: the Task Force for diabetes, pre-diabetes, and cardiovascular diseases of the European Society of Cardiology (ESC) and the European Association for the Study of Diabetes (EASD). Eur Heart J. 2019;41(2):255-323. https://doi.org/10.1093/ eurheartj/ehz486.

29. O'Sullivan JJ, Conroy RM, MacDonald K, McKenna TJ, Maurer BJ. Silent ischaemia in diabetic men with autonomic neuropathy. Brit Heart J. 1991;66(4):313-5.

30. Garofolo M, Gualdani E, Giannarelli R, Aragona M, Campi F, Lucchesi D, et al. Microvascular complications burden (nephropathy, retinopathy and peripheral polyneuropathy) affects risk of major vascular events and allcause mortality in type 1 diabetes: a 10-year follow-up study. Cardiovasc Diabetol. 2019;18(159):1-16. https://doi.org/10.1186/s12933-019-0961-7.

31. Simó R, Bañeras J, Hernández C, Rodríguez-Palomares J, Valente F, Gutierrez $L$, et al. Diabetic retinopathy as an independent predictor of subclinical cardiovascular disease: baseline results of the PRECISED study. BMJ Open Diab Res Care. 2019;7(1):e000845. https://doi.org/10.1136/bmjdr c-2019-000845

32. Carbonell M, Castelblanco E, Valldeperas X, Betriu À, Traveset A, GranadoCasas $M$, et al. Diabetic retinopathy is associated with the presence and burden of subclinical carotid atherosclerosis in type 1 diabetes. Cardiovasc Diabetol. 2018;17(66):1-10. https://doi.org/10.1186/s1293 3-018-0706-z.

33. Alonso N, Traveset A, Rubinat E, Ortega E, Alcubierre N, Sanahuja J, et al. Type 2 diabetes-associated carotid plaque burden is increased in patients with retinopathy compared to those without retinopathy. Cardiovasc Diabetol. 2015;14(33):1-9. https://doi.org/10.1186/s12933-015-0196-1.

34. Distiller LA, Joffe BI, Melville V, Welman T, Distiller GB. Carotid artery intima-media complex thickening in patients with relatively long-surviving type 1 diabetes mellitus. J Diabetes Complicat. 2006;20(5):280-4. https://doi.org/10.1016/j.jdiacomp.2005.07.012. 
35. Ichinohasama K, Kunikata H, Ito A, Yasuda M, Sawada S, Kondo K, et al. The relationship between carotid intima-media thickness and ocular circulation in type-2 diabetes. J Ophthalmol. 2019;2019:1-8. https://doi. org/10.1155/2019/3421305.

36. Liu Y, Teng X, Zhang W, Zhang R, Liu W. Association between diabetic retinopathy and subclinical atherosclerosis in China: results from a community-based study. Diab Vasc Dis Res. 2015;12(5):366-72. https:// doi.org/10.1177/1479164115591744.

37. Araszkiewicz A, Rogowicz-Frontczak A, Zozulinska-Ziolkiewicz D, Pilacinski S, Wykretowicz A, Wierusz-Wysocka B. Presence of retinopathy in type 1 diabetic patients is associated with subclinical macroangiopathy. Scand J Clin Lab Invest. 2011;71(7):563-8. https://doi.org/10.3109/00365 513.2011.593268.

38. Cardoso CRL, Salles GC, Leite NC, Salles GF. Prognostic impact of carotid intima-media thickness and carotid plaques on the development of micro- and macrovascular complications in individuals with type 2 diabetes: the Rio de Janeiro type 2 diabetes cohort study. Cardiovasc Diabetol. 2019;18(2):1-13. https://doi.org/10.1186/s12933-019-0809-1.

39. Hjelmgren O, Stromberg U, Gellerman K, Thurin A, Zetterberg M, Bergstrom $\mathrm{G}$. Does retinopathy predict stroke recurrence in type 2 diabetes patients: a retrospective study? PLoS ONE. 2019;14(1):e0210832. https:// doi.org/10.1371/journal.pone.0210832.

40. Yun Y-W, Shin M-H, Lee Y-H, Rhee J-A, Choi J-S. Arterial stiffness is associated with diabetic retinopathy in Korean type 2 diabetic patients. J Prev Med Public Health. 2011;44(6):260-6. https://doi.org/10.3961/jpmph .2011.44.6.260.
41. Cheung N, Liew G, Wong TY. Current approaches to retinopathy as a predictor of cardiovascular risk. In: Hammes H-P, Porta M, editors. Experimental approaches to diabetic retinopathy. Basel: Karger; 2009. p. 203-19.

42. Davis TM, Hunt K, McAullay D, Chubb SA, Sillars BA, Bruce DG, et al. Continuing disparities in cardiovascular risk factors and complications between aboriginal and Anglo-Celt Australians with type 2 diabetes: the Fremantle Diabetes Study. Diabetes Care. 2012;35(10):2005-11. https:// doi.org/10.2337/dc12-0225.

43. Patton N, Pattie A, MacGillivray T, Aslam T, Dhillon B, Gow A, et al. The association between retinal vascular network geometry and cognitive ability in an elderly population. Invest Ophth Vis Sci. 2007;48(5):19952000. https://doi.org/10.1167/iovs.06-1123.

44. Simó R, Stitt AW, Gardner TW. Neurodegeneration in diabetic retinopathy: does it really matter? Diabetologia. 2018;61(9):1902-12. https://doi. org/10.1007/s00125-018-4692-1.

45. Prasad S, Sajja RK, Naik P, Cucullo L. Diabetes mellitus and blood-brain barrier dysfunction: an overview. J Pharmacovigil. 2014;2(2):125. https:// doi.org/10.4172/2329-6887.1000125.

\section{Publisher's Note}

Springer Nature remains neutral with regard to jurisdictional claims in published maps and institutional affiliations.
Ready to submit your research? Choose BMC and benefit from:

- fast, convenient online submission

- thorough peer review by experienced researchers in your field

- rapid publication on acceptance

- support for research data, including large and complex data types

- gold Open Access which fosters wider collaboration and increased citations

- maximum visibility for your research: over $100 \mathrm{M}$ website views per year

At BMC, research is always in progress.

Learn more biomedcentral.com/submissions 